\title{
Correction to: Quasi-DNS Dataset of a Piloted Flame with Inhomogeneous Inlet Conditions
}

\author{
Thorsten Zirwes $^{1,2}$ (D) Feichi Zhang ${ }^{2}$ - Peter Habisreuther ${ }^{2}$ - Maximilian Hansinger ${ }^{3}$. \\ Henning Bockhorn ${ }^{2} \cdot$ Michael Pfitzner $^{3} \cdot$ Dimosthenis Trimis $^{2}$
}

Published online: 3 March 2021

(C) The Author(s) 2021

\section{Correction to: Flow, Turbulence and Combustion (2020) 104:997-1027 https://doi.org/10.1007/s10494-019-00081-5}

The article Quasi-DNS Dataset of a Piloted Flame with Inhomogeneous Inlet Conditions written by Thorsten Zirwes, Feichi Zhang, Peter Habisreuther, Maximilian Hansinger, Henning Bockhorn, Michael Pfitzner, Dimosthenis Trimis, was originally published Online First without Open Access. After publication in volume 104, issue 4, page 997-1027 the authors decided to opt for Open Choice and to make the article an Open Access publication. Therefore, the copyright of the article has been changed to (C) The Author(s) 2020 and the article is forthwith distributed under the terms of the Creative Commons Attribution CC BY.

The original article has been corrected.

Open Access This article is licensed under a Creative Commons Attribution 4.0 International License, which permits use, sharing, adaptation, distribution and reproduction in any medium or format, as long as you give appropriate credit to the original author(s) and the source, provide a link to the Creative Commons licence, and indicate if changes were made. The images or other third party material in this article are included in the article's Creative Commons licence, unless indicated otherwise in a credit line to the material. If material is not included in the article's Creative Commons licence and your intended use is not permitted by statutory regulation or exceeds the permitted use, you will need to obtain permission directly from the copyright holder. To view a copy of this licence, visit http://creativecommons.org/licenses/by/4.0/.

The original article can be found online at https://doi.org/10.1007/s10494-019-00081-5.

Thorsten Zirwes

thorsten.zirwes@kit.edu

1 Steinbuch Centre for Computing, Karlsruhe Institute of Technology, Hermann-von-Helmholtz-Platz 1, 76344 Eggenstein-Leopoldshafen, Germany

2 Engler-Bunte-Institute, Division of Combustion Technology, Karlsruhe Institute of Technology, Engler-Bunte-Ring 1, 76131 Karlsruhe, Germany

3 Institute for Thermodynamics, Bundeswehr University Munich, Werner-Heisenberg-Weg 39, 85577 Neubiberg, Germany 